\title{
How Men with Prostate Cancer Choose Specialists: A Qualitative Study
}

\author{
Tammy Jiang, MPH, Christian H. Stillson, MPH, Craig Evan Pollack, MD, MHS, \\ Linda Crossette, MPH, Michelle Ross, PhD, Archana Radhakrishnan, MD, and \\ David Grande, MD, MPA
}

Objective: The specific specialist that a patient sees can have a large influence on the type of care they receive.

Methods: We administered semistructured interviews with 47 men diagnosed with prostate adenocarcinoma between 2012 and 2014. Telephone interviews were recorded, transcribed, and analyzed using a systematic thematic approach.

Results: Three profiles of patients emerged for choosing specialists: active (21.3\%), partially active (53.2\%), and passive (25.5\%). Active patients conducted substantial research when choosing a diagnosing urologist and a treating specialist: they searched online, consulted other men with prostate cancer, and/or visited multiple specialists for opinions. Partially active patients took only 1 additional step to find a treating specialist on their own after receiving a referral from their diagnosing urologist. Passive patients relied exclusively on referrals from their primary care physicians (PCPs) and diagnosing urologists.

Conclusion: The majority of patients relied on their PCPs for referrals to diagnosing urologists and on their diagnosing urologists to choose the treating specialist. Given these findings and the significance of specialist choice in determining treatment, it is important that PCPs recognize their indirect but potentially important effect on treatment choice when making referrals for prostate cancer. PCPs should consider counseling patients about seeking second opinions from providers with different treatment perspectives and participating in treatment decisions. (J Am Board Fam Med 2017;30:220-229.)

Keywords: Adenocarcinoma, Choice Behavior, Counseling, Primary Care Physicians, Prostatic Neoplasms, Referral and Consultation, Research, Specialization, Telephone

Prostate cancer is one of the leading types of cancer diagnosed among men of all races in the United States. ${ }^{1}$ Choosing a treatment for localized prostate cancer is challenging for patients because the optimal treatment strategy is unclear ${ }^{2}$ and involves weighing trade-offs between uncertain risks and

This article was externally peer reviewed.

Submitted 17 May 2016; revised 30 September 2016; accepted 11 October 2016.

From the Brown University School of Public Health, Providence, RI (TJ); the Division of General Internal Medicine, Perelman School of Medicine, University of Pennsylvania, Philadelphia (CHS, LC, DG); the Department of Medicine, Johns Hopkins School of Medicine and Bloomberg School of Public Health, Baltimore, MD (CEP, AR); the Department of Biostatistics and Epidemiology, Perelman School of Medicine, University of Pennsylvania, Philadelphia (MR); and the Leonard Davis Institute of Health Economics, Perelman School of Medicine, University of Pennsylvania, Philadelphia (DG). benefits related to quality of life, morbidity, and mortality. ${ }^{3}$ Prior research examining patient decision making for prostate cancer has focused on patients' involvement in decision making about treatment, ${ }^{4-7}$ patient preferences, ${ }^{8-10}$ and the impact of decision aids on treatment choices. ${ }^{11-13}$ However, there is a paucity of research on how men with prostate cancer select specialists and specifically the role of primary care providers (PCPs) in influencing the choice of specialist.

Funding: Funding for this study was provided by the National Institute on Minority Health and Health Disparities (P60MD006900). The salary of CEP is supported by the National Cancer Institute and Office of Behavioral and Social Sciences (K07 CA151910).

Conflict of interest: none declared.

Corresponding author: David Grande, MD, MPA, Colonial Penn Center 407, 3641 Locust Walk, Philadelphia, PA 19104 (E-mail: dgrande@wharton.upenn.edu). 
Typically, a PCP screens a patient for prostate cancer, then refers him to a urologist, who diagnoses the cancer through a biopsy. After diagnosis, patients may stay with their diagnosing urologist for treatment, change to a different urologist, and/or visit a radiation oncologist. Understanding how men with prostate cancer choose both their diagnosing and treating specialists is particularly important because who they see has a large effect on the ultimate treatment that the men receive. ${ }^{3,14}$ For example, one study found that diagnosing urologists who also offer treatment account for more of the variation in initial treatment than patient and tumor characteristics. ${ }^{14}$ Additional studies have demonstrated that urologists and radiation oncologists are both more likely to recommend the treatment they themselves deliver for men with similar clinical characteristics. ${ }^{15-17}$ In some instances, a treatment plan is even chosen on a patient's behalf by his specialist, with little input from the patient himself. ${ }^{18}$

Studies not specific to prostate cancer have shown that patients rely on referrals from their physicians to decide where to have surgery. ${ }^{19-21}$ In general, the reputation of the physician and health care organization are most important to patients when selecting a health care provider. ${ }^{22}$ The methods patients use to select physicians can often be informal. Most patients ask their PCPs, friends, and family about the quality of providers rather than reviewing public reports or conducting online searches. ${ }^{23,24}$ In one survey, among those who had seen a specialist, nearly $60 \%$ relied exclusively on a referral from their PCP to choose their specialist. ${ }^{25}$

Little is known about how patients choose cancer specialists and whether it is similar to other previously described patterns of seeking out specialty care. The case of localized prostate cancer is uniquely important given that it is common among men, PCPs play an important role in shared decision making regarding whether to screen in the first place, the treatment choices for localized cancer are sensitive to patient preferences, and the choice of specialist can have a large influence on decision making. In this study, we used qualitative methods to explore the ways men diagnosed with prostate cancer chose their specialists and the characteristics they looked for in doctors. Specifically, we examined the role of PCPs and their referrals versus more consumer-oriented behaviors when patients were choosing a cancer specialist.

\section{Methods}

We recruited participants from the Philadelphia Area Prostate Cancer Access Study ( $\mathrm{P}^{2}$ Access) who indicated willingness to be recontacted. $\mathrm{P}^{2}$ Access is a survey study of men diagnosed with localized prostate cancer in the Greater Philadelphia region between 2012 and 2014. These men were identified from the Pennsylvania Cancer Registry. A total of 326 survey respondents agreed to be recontacted and had a phone number on file. We purposefully sampled respondents based on their potential geographic access to urologists and radiation oncologists. Geographic access was determined by the number of these providers within a 30-minute driving distance from home, with patients divided into quintiles. We randomly selected 30 respondents from high ( $>102$ practices within 30 minutes) and low ( $<13$ practices within 30 minutes) access quintiles to participate in a phone interview. A convenience sample of 9 additional respondents were invited for an interview (eg, participants calling to respond to a request for missing survey data); one of these men was from a high access area and the remainder were from neither high nor low access areas. Of the 72 respondents who were invited to participate, 53 men (73.6\%) agreed and were interviewed between June and August 2015. Six men were subsequently excluded because of disclosures during their interview about a secondary cancer (eg, their prostate cancer was secondary to other cancer), leaving 47 men included in this study. We ended recruitment when we reached thematic saturation in the qualitative analysis.

We developed a semistructured interview guide with open-ended questions to examine men's experiences with selecting physicians, navigating the health care system, and choosing a treatment. We asked specifically about how men selected the urologist who diagnosed their prostate cancer (diagnosing urologist) and the physician who ultimately treated their prostate cancer (treating specialist), recognizing that, for some men, these physicians would be the same. We revised the interview guide in an iterative fashion during data collection to increase the richness of responses. All interviews were conducted over the phone by a member of the study team (TJ) trained in conducting in-depth interviews. The mean interview length was $24 \mathrm{~min}$ utes (range, 12-64 minutes). 
Table 1. Demographic Characteristics of Study Participants - Men with Recently Diagnosed Localized Prostate Cancer

\begin{tabular}{|c|c|c|c|c|}
\hline & $\begin{array}{l}\text { All Interview Participants } \\
\qquad(\mathrm{n}=47)^{*}\end{array}$ & $\begin{array}{l}\text { Active Patients } \\
\quad(\mathrm{n}=10)^{*}\end{array}$ & $\begin{array}{l}\text { Partially Active Patients } \\
\qquad(\mathrm{n}=25)^{*}\end{array}$ & $\begin{array}{l}\text { Passive Patients } \\
\qquad(\mathrm{n}=12)^{*}\end{array}$ \\
\hline Age (mean, range) & $66.7(59-86)$ & $70.6(49$ to 86$)$ & 63.5 (50 to 76$)$ & $70(56$ to 86$)$ \\
\hline \multicolumn{5}{|c|}{ Educational Attainment N (\%) } \\
\hline High school or less & $15(31.9 \%)$ & $1(10 \%)$ & $8(32 \%)$ & $6(50 \%)$ \\
\hline Some college & $9(19.1 \%)$ & $0(0 \%)$ & $8(32 \%)$ & $1(8.3 \%)$ \\
\hline College or more & $22(46.8 \%)$ & $9(90 \%)$ & $9(36 \%)$ & $4(33.3 \%)$ \\
\hline \multicolumn{5}{|c|}{ Total Household Income N (\%) } \\
\hline$<\$ 50,000$ & $14(29.8 \%)$ & $1(10 \%)$ & $6(24 \%)$ & $7(58.3 \%)$ \\
\hline$\geq \$ 50,000$ & $30(63.8 \%)$ & $8(80 \%)$ & $18(72 \%)$ & $4(33.3 \%)$ \\
\hline \multicolumn{5}{|l|}{ Race N (\%) } \\
\hline White & $38(80.9 \%)$ & $9(90 \%)$ & $21(84 \%)$ & $8(66.7 \%)$ \\
\hline Black & $9(19.1 \%)$ & $1(10 \%)$ & $4(16 \%)$ & $4(33.3 \%)$ \\
\hline \multicolumn{5}{|c|}{ Employment Status N (\%) } \\
\hline Employed & $15(31.9 \%)$ & $5(50 \%)$ & $8(32 \%)$ & $2(16.7 \%)$ \\
\hline Unemployed & $2(4.3 \%)$ & $1(10 \%)$ & $1(4 \%)$ & $0(0 \%)$ \\
\hline Disabled & $4(8.5 \%)$ & $0(0 \%)$ & $2(8 \%)$ & $2(16.7 \%)$ \\
\hline Retired & $25(53.2 \%)$ & $3(30 \%)$ & $14(56 \%)$ & $8(66.7 \%)$ \\
\hline \multicolumn{5}{|c|}{ Insurance Status N (\%) } \\
\hline Medicare & $20(42.6 \%)$ & $7(70 \%)$ & $6(24 \%)$ & $7(58.3 \%)$ \\
\hline Medicaid & $2(4.3 \%)$ & $0(0 \%)$ & $1(4 \%)$ & $1(8.3 \%)$ \\
\hline Private & $25(53.2 \%)$ & $3(30 \%)$ & $18(72 \%)$ & $4(33.3 \%)$ \\
\hline
\end{tabular}

${ }^{*}$ Certain demographic characteristics do not add up to the total number of participants because some participants did not provide all demographic information.

Interview recordings were professionally transcribed and uploaded into the qualitative analysis software NVivo 10 (QSR International) to facilitate a systematic thematic analysis of content. A representative sample of transcripts was reviewed to develop a coding dictionary comprising both structural and contextual codes. Eleven transcripts were independently double-coded (by TJ and CS) to develop, then validate, our codebook. Intercoder agreement was assessed using the Cohen $\kappa$ statistic. Codes with a $\kappa$ value $<0.7$ were jointly reviewed, and discrepancies were resolved via consensus. Intercoder agreement across all codes following review was high, with a mean $\kappa$ of 0.91 . The remaining transcripts were then coded by a single investigator (TJ). After coding all transcripts, content was grouped into common themes and discussed among the full study team. We identified major themes via consensus through the review of transcripts and coding memos.

This study was approved by the University of Pennsylvania Institutional Review Board. Informed consent was obtained from all participants over the phone. Participants were compensated \$25 for their time.

\section{Results}

Characteristics of the 47 participants are given in Table 1. The mean age of participants was 67 years (range, 49-86 years). Among the participants, 38 (81\%) identified themselves as white and 9 (19\%) as black; 22 participants (47\%) had at least a college degree and 30 (64\%) reported annual household incomes $>\$ 50,000$. At the time of diagnosis, the majority of participants had private health insurance $(\mathrm{n}=25)$ or Medicare $(\mathrm{n}=20)$; the remaining 2 had Medicaid.

Thematic analysis of the interviews revealed clusters of behavioral patterns that indicated differences in the ways that patients chose their treating specialists. The first cluster of men described searching the Internet for doctors, consulting other men with prostate cancer to understand their experiences with providers and treatment, and seeking second opinions. Men who displayed at least 2 of these behaviors were categorized as "active pa- 
tients" $(\mathrm{n}=10)$. The second cluster of men were categorized as "partially active patients" $(\mathrm{n}=25)$. These men described taking 1 additional step, beyond receiving referrals from their diagnosing urologist, to find a treating specialist on their own. The third cluster of men relied exclusively on their PCP's referral to a diagnosing urologist and also relied exclusively on their diagnosing urologist's referral to a treating specialist. We categorized these men as "passive patients" $(\mathrm{n}=12)$. Active patients tended to be from a higher socioeconomic group compared with passive patients (Table 1). In addition, most active patients graduated from college and had a household income $>\$ 50,000$.

Men in this study were purposefully sampled based on the number of specialists within a 30minute drive of their home address. We found that there were no differences in specialist-seeking behaviors between participants who lived in areas with high and low potential geographic access to prostate cancer specialists.

\section{Active Patients}

Five active patients (50\%) chose their own diagnosing urologist after an abnormal prostate-specific antigen test (Table 2). Their reasons for choosing their own diagnosing urologist varied: Some patients chose a urologist whom they had seen previously for a different health condition. Others were referred to a urology practice, but then researched and chose a specific diagnosing urologist within the practice on their own. One patient said, "[My PCP] actually referred me to a group of urologists. I was the one who chose [my diagnosing urologist].... I liked his bio. He was one of the younger ones, but with experience with new technology. . . . I looked up on the Internet and chose my own specific [diagnosing] urologist. Once I was diagnosed with cancer, well then, my choice of [treating specialists] was a lot more complicated."

Active patients described considering a myriad of factors when choosing a treating specialist ( $\mathrm{Ta}-$ ble 3). They considered years of experience, number of surgeries performed, reputation, communication skills, and involvement in research. Patients discussed wanting the most qualified doctors to treat their cancer and for themselves to have an active role in the treatment decision-making process. When describing what he looked for in a doctor, 1 respondent said, "I went online and there's all kinds of write-ups and things and infor- mation about each doctor, and [my treating specialist] sounded like a good choice . . . his experience level and reputation that was reflected in the write-ups about him that I read." Another participant said, "After the biopsy came back and showed the cancer was present, [my diagnosing urologist] suggested there were 3 forms of treatment, but really only suggested surgery. I said fine, let me do some thinking. I researched everything and got a second and third opinion at [treatment center 1] and [treatment center 2] and made a decision to have a surgery at [treatment center 2]."

Active patients also spoke to other men with prostate cancer to understand their experiences with treating specialists and certain treatments. One patient said, "I've talked to [my family] and that is why I switched to this [treating urologist] that my brother has." Another patient said, "[I talked] to people who have had a procedure to see what their results have been. And I did talk to a few people who had the procedures done for prostate cancer and came up to the conclusion that this is what was best for me too."

All active patients described seeking second opinions from treating specialists to compare their specialists' experience levels and to learn more about various treatment options. One man said, "So when ... your life is in the balance, why would not you get a second or third opinion? That is why I got a second and third opinion . . . I wanted to hear what [the treating specialists] had to say."

\section{Partially Active Patients}

A total of 21 partially active patients (84\%) went to the diagnosing urologist or urology practice that their PCP referred them to. Of these patients, 18 $(86 \%)$ did not know the reasons why their PCP referred them to the specific diagnosing urologist, nor did they choose their own diagnosing urologist if they were referred to a practice. One patient who was referred to a urology practice said, "I kind of was just assigned to [my diagnosing urologist] when I made the appointment. I was not sure who I was gonna see when I went into the practice.” Another patient said, "I trusted my $[\mathrm{PCP}]$ and I really trusted that he would refer me to someone who is competent."

When searching for their treating specialists, partially active patients reported looking for doctors who had a good bedside manner and high experience levels (Table 3). One participant said, 
Table 2. Differences in How Men with Prostate Cancer Find Specialists

\begin{tabular}{lll}
\hline Theme & \multicolumn{2}{c}{ Representative Quote } \\
\hline Active Patients $(\mathrm{n}=10)$ & $\mathrm{N}(\%)$
\end{tabular}

Selecting a Diagnosing Urologist

Referral Received a referral from PCP but also researched/ "I was the one who chose [the diagnosing chose their own diagnosing urologist urologist]... I looked up on the internet and chose my own specific [diagnosing] urologist."

\section{Selecting a Specialist for Treatment}

Referral Received referral/treatment recommendation from "I just didn't feel comfortable with just saying diagnosing urologist but ultimately chose a okay, I'll have [my diagnosing urologist] do different treating specialist the surgery. Because the first question I asked him was how many surgeries have you done. He said about 200, okay? ... And I saw a [different treating specialist] ... and he's got a national reputation."

Online Research Did online research

"I just looked at their [online] records and how deep a history they had doing this operation, and [the doctor] had done far more operations of this kind than the other fellow ..."

Consulted Friends- Talked to other men who had prostate cancer Family-Coworkers

"I spoke to a number of people that I knew that had had similar cancer. I then had a choice to make in my own mind between two hospitals."

Second opinion Sought second opinion after receiving a treatment "I get a second opinion about buying a garage recommendation/referral to another specialist from urologist door. Or when you buy a car, you go to a second or third dealer... that's just a smart way to do things. So when potentially your life is in the balance, why wouldn't you get a second or third opinion?"

\begin{tabular}{l}
\hline Partially Active Patients (n \\
$\begin{array}{l}\text { Selecting a Diagnosing Urologist } \\
\text { Referral }\end{array}$ \\
$\begin{array}{l}\text { Went to diagnosing urologist they were referred } \\
\text { to by PCP without additional searches }\end{array}$
\end{tabular}

Existing Urologist Saw previous urologist they were referred to

"No, I didn't know nothing about [the specialist] until I was told to go there. He's a really nice guy."

$9(90 \%)$

$10(100 \%)$

"Well, I already knew that guy from being there once or twice before, and he is-I really liked him. I had a lot of confidence in him."

\section{Selecting a Specialist for Treatment}

Referral Received referral/treatment recommendation from "[My diagnosing urologist] referred me to a diagnosing urologist but ultimately chose a radiologist... I went to [a different different treating specialist healthcare facility] also-talked to a doctor there. That's when we decided to have prostate treatment."

Online Research Did online research

"I went to the computer and looked things up about prostate cancer and everything."

Consulted Friends- Talked to friends-family-co-workers Family-Co-

"Just word of mouth, knowing the [hospital] system. And my wife just told me, my son-inlaw has been a patient for them... He just had good words to say about him. He had never had any problems with him."

Second Opinion Sought second opinion after receiving a treatment recommendation/referral to another specialist from urologist

"We just feel any time there's surgery involved, 13 (52\%)

Did not seek second opinion after receiving a treatment recommendation/referral to another specialist from urologist we should get a second opinion. It's just prudent."

"We had no second opinion ... I just want to get this over with." 
Table 2. Continued

\begin{tabular}{|c|c|c|c|}
\hline \multicolumn{2}{|r|}{ Theme } & \multicolumn{2}{|l|}{ Representative Quote } \\
\hline \multicolumn{3}{|c|}{ Passive Patients $(\mathrm{n}=12)$} & $\mathrm{N}(\%)$ \\
\hline \multicolumn{4}{|c|}{ Selecting a Diagnosing Urologist } \\
\hline Referral & $\begin{array}{l}\text { Went to diagnosing urologist they were referred } \\
\text { to by PCP without additional searches }\end{array}$ & $\begin{array}{l}\text { "I just went with what my family doctor } \\
\text { said ... I just went with what was suggested, } \\
\text { and I was satisfied." }\end{array}$ & $9(75 \%)$ \\
\hline Existing Urologist & $\begin{array}{l}\text { Saw previous urologist they were referred to by } \\
\text { PCP }\end{array}$ & $\begin{array}{l}\text { "Because a few years back, I had a urology } \\
\text { problem ... And I called that particular } \\
\text { practice, and he was the next doctor that had } \\
\text { an appointment, so I saw him." }\end{array}$ & $3(25 \%)$ \\
\hline \multicolumn{4}{|c|}{ Selecting a Specialist for Treatment } \\
\hline Referral & $\begin{array}{l}\text { Saw only their diagnosing urologist and the } \\
\text { treating specialists they were referred to by } \\
\text { their diagnosing urologist for treatment }\end{array}$ & $\begin{array}{l}\text { "[My diagnosing urologist }] \text { sent me over to } \\
\text { radiation oncology and that's why I saw } \\
\text { [the radiation oncologist }] \ldots \text { and then [the } \\
\text { radiation oncologist }] \text { started doing the } \\
\text { radiation." }\end{array}$ & $12(100 \%)$ \\
\hline Second Opinion & $\begin{array}{l}\text { Did not seek second opinion after receiving a } \\
\text { treatment recommendation/referral to another } \\
\text { specialist from urologist }\end{array}$ & $\begin{array}{l}\text { "I felt that-after my first meeting [with the } \\
\text { urologist], .. . I didn't need a second } \\
\text { opinion." }\end{array}$ & $11(91.6 \%)$ \\
\hline
\end{tabular}

${ }^{*}$ One passive patient sought a separate specialist to get a stress test because of his cardiac condition before undergoing surgery. The other 11 passive patients did not seek other specialists.

PCP, primary care physician.

"Well, [my wife and I] looked [my treating specialist] up on the internet. He got good patient ratings. And we had an initial meeting with him, and we felt we had a good rapport with him. We were comfortable with ... the way he laid things out, with his experience- - he'd done 4000 of these kinds of surgeries."

Partially active patients were generally split on seeking second opinions. Some patients discussed wanting to find the right treating specialist, whereas others did not seek second opinions because of their perception that cancer needed to be treated immediately. A patient who sought a second opinion said, "Everybody says get a second opinion, get a second opinion. . . . So the better informed you are, the better decisions you make, I think." Conversely, a patient who did not seek a second opinion said, "I did not even think about a second opinion. I just told [my diagnosing urologist] once he told me about the results of my biopsy that . . . 'how soon can I get there to get the surgery done?" Partially active patients' reasons for not getting a second opinion were related to feeling a sense of urgency after receiving their prostate biopsy results. One man said, "But now that I went through the whole procedure and the surgery, I really wished I would have either went to [cancer center 1] or [cancer center 2] because that is all they do. But at the time, I was so devastated that I had [cancer], and more upset, and wanted to hurry up and just get it out of me, so I chose to just have it taken out."

\section{Passive Patients}

Passive patients described relying exclusively on their PCP's referral to a diagnosing urologist, followed by their diagnosing urologist's referral to a treating specialist if their diagnosing urologist did not offer treatment. Similar to partially active patients, passive patients did not know why their PCP referred them to a particular diagnosing urologist. When asked about why his PCP referred him to a specific urologist, one patient said, "I do not [know]. My guess is [my PCP] just thought [the diagnosing urologist] was good. I do not know."

Most of these patients described a trust in their physicians that seemed to obviate the need for a second opinion. When describing his treating specialist, one participant said, "He just sat down, talked to me and gave me options, told me what was best and what I could do. And he also recommended if I wanted to get a second opinion, but I said no. I feel as though you are-I trust you. That is another word, trust. You have got to trust the doc." Doctors' communication skills played an important role in how passive patients gauged their trustworthiness. One respondent said, "The way he talked to me, the way we discussed things ... he 
Table 3. Differences in What Men with Prostate Cancer Look for in a Treating Specialist

\begin{tabular}{|c|c|c|c|}
\hline \multicolumn{2}{|c|}{ Theme } & \multicolumn{2}{|l|}{ Representative Quote } \\
\hline \multicolumn{3}{|c|}{ Active Patients $(\mathrm{n}=10)$} & $N(\%)$ \\
\hline Experience & Experience level & $\begin{array}{l}\text { "... you want somebody that's done as many as you } \\
\text { can find that seems like an okay guy because } \\
\text { there's nothing like experience, and in } \\
\text { surgery ... So I had two doctors who had done } \\
\text { thousands of these things." }\end{array}$ & $7(70 \%)$ \\
\hline \multirow[t]{2}{*}{ Reputation } & Reputation of doctor & $\begin{array}{l}\text { "I wanted to see the best person at [hospital] for the } \\
\text { radiology. And obviously, it was the head of } \\
\text { radiology. So, that's the reason I chose him. And } \\
\text { it was a good choice... He was extremely good } \\
\text { in his field." }\end{array}$ & $8(80 \%)$ \\
\hline & Research & $\begin{array}{l}\text { "I wanted to be with a hospital that was up-to-date } \\
\text { in the latest procedures, technologies, diagnostics, } \\
\text { and I thought that both hospitals had that." }\end{array}$ & $2(20 \%)$ \\
\hline Bedside Manner & Bedside manner & $\begin{array}{l}\text { "I was happy when [my specialist] was very open } \\
\text { and communicative. His communication skills } \\
\text { were excellent ... he said, prepare your questions. } \\
\text { I'll answer any-all your questions." }\end{array}$ & $6(60 \%)$ \\
\hline \multicolumn{3}{|c|}{ Partially Active Patients $(\mathrm{n}=25)$} & $\mathrm{N}(\%)$ \\
\hline Experience & Experience level & $\begin{array}{l}\text { "Well, we looked him up on the internet. He got } \\
\text { good patient ratings. And we had an initial } \\
\text { meeting with him, and we felt we had a good } \\
\text { rapport with him. We were comfortable with the } \\
\text { way he laid things out, with his experience-he'd } \\
\text { done } 4000 \text { of these kinds of surgeries." }\end{array}$ & $9(36 \%)$ \\
\hline Reputation & Reputation of facility & $\begin{array}{l}\text { "Well, one thing I look for in a doctor is where } \\
\text { they work... one reason I like [this hospital] is } \\
\text { because it's a teaching hospital ... since this is a } \\
\text { teaching hospital, most of the physicians are up to } \\
\text { the moment with current trends and discoveries } \\
\text { in the medical fields..." }\end{array}$ & $8(32 \%)$ \\
\hline Bedside Manner & Bedside manner & $\begin{array}{l}\text { "Gee, you know I guess just competence, somebody } \\
\text { who gives you the feeling that they care. Like I } \\
\text { said, I like somebody who spends a little bit of } \\
\text { time with you. Like when I went to that urologist } \\
\text { I felt like I was on the treadmill, an assembly line. } \\
\text { When I got out of there, I bet nobody gets out of } \\
\text { here without getting biopsy or another } \\
\text { appointment." }\end{array}$ & $12(48 \%)$ \\
\hline Trustworthy & Trustworthy & $\begin{array}{l}\text { "He didn't beat around the bush. You know what I } \\
\text { mean? He more or less told you what was gonna } \\
\text { happen, and that's what happened." }\end{array}$ & $9(36 \%)$ \\
\hline \multicolumn{3}{|c|}{ Passive Patients $(\mathrm{n}=12)$} & $\mathrm{N}(\%)$ \\
\hline Experience & Experience level & $\begin{array}{l}\text { "[My doctor }] \text { has been in this business for a long } \\
\text { time, so. That's why I really went to him." }\end{array}$ & $2(16.7 \%)$ \\
\hline Bedside Manner & Bedside manner & $\begin{array}{l}\text { "Well, I like a doctor that I can sit down and talk } \\
\text { to ... a doctor who'll spend a little time with } \\
\text { you ... That is something that's important to me. } \\
\text { Somebody I can talk to." }\end{array}$ & $6(50 \%)$ \\
\hline Trustworthy & Trustworthy & $\begin{array}{l}\text { "Well, see I didn't know the difference between } \\
\text { either doctor but, after he told me what he does } \\
\text { and done this, I had everything in my heart to } \\
\text { trust him ... I felt safe and secure right... I } \\
\text { never had a problem or anything, so I felt good." }\end{array}$ & $5(41.6 \%)$ \\
\hline
\end{tabular}

made me feel comfortable of what I was going to go through." Good communication with their treating specialist engendered feelings of trust and seemed to be sufficient criteria for these men in making this choice.
This contrasts with active patients, who scrutinized the decisions of doctors. One active patient said, “. . . after meeting with [my diagnosing urologist] and discussing the surgery, I came to that [treatment] conclusion on my own, after having 
consulted with my oncologist and my primary care doctor. To be frank about it, when your medical practice is doing surgery, that is obviously one of the things that you are gonna recommend."

In addition, some passive patients expressed a sense of urgency to treat their cancer immediately. They added that if they spent more time searching for doctors, it would only delay the onset of treatment. One participant commented, "All I want to do is get well and get this out of my body." Another man said, "I was not about to wait a year. Cancer is not something that goes away ... it has to get worse sooner or later."

\section{Discussion}

To our knowledge, this is the first study to examine qualitatively how men diagnosed with localized prostate cancer select specialists. Our study has 3 key findings. First, patterns of treating specialistseeking behaviors varied greatly, and from these, 3 patient profiles emerged: active, partially active, and passive. Active patients conducted substantial research when deciding between multiple treating specialists. In addition, they frequently performed online searches, spoke with other men who had prostate cancer, and/or visited several treating specialists for multiple opinions. Partially active patients only sometimes sought second opinions, whereas passive patients relied almost exclusively on referrals from their PCP and diagnosing urologists. The results underscore the diverse health care-seeking behaviors known to exist among patients and builds on previous research that shows there is substantial variation in the degree of consumerism among patients and that many patients are generally passive health consumers. $^{24,26}$

Second, although there were different specialistseeking patterns, the majority of men in our study relied heavily on PCP referrals to diagnosing urologists and on diagnosing urologist referrals to treating specialists. Most patients did very little additional research or "shopping" for specialists. Many of the partially active and passive patients reported not knowing the reasons why their PCPs referred them to a specific diagnosing urologist and not knowing anything about the diagnosing urologist before their visit. This finding is consistent with a scoping review that found that most patients do not look for the highest-quality doctors and tend to stay with their current provider and rely on their PCP's advice. ${ }^{26}$ Another key finding is that, although localized prostate cancer is not treated on an emergent basis, patients' concerns about the urgency of treating cancer further added to the influence of referrals. This reliance on referrals suggests that the referring doctor likely has an unexpectedly strong influence on the treatment received. Previous studies demonstrate that providerlevel effects are larger than patient-level or biologic effects, ${ }^{3,14-17}$ but more research is needed to elucidate the influence of PCPs on treatment, because they are usually the ones who start the chain of referrals.

Third, when men with prostate cancer evaluated treating specialists, active patients often used the physician's case volume, job title, involvement in research, and years of experience as proxies for quality. Partially active and passive patients often emphasized trustworthiness and bedside manner in addition to experience. PCPs should be cognizant of the differences in how patients perceive the quality of physicians when discussing the selection of a particular specialist.

This study has several limitations. First, the geographic scope of this study is limited to the Greater Philadelphia region, one that includes 5.3 million residents living in urban and suburban areas. Therefore, it may not be representative of patient experiences in other regions. For example, insurance networks were rarely mentioned as influencing specialist choice. This may vary by insurance market and may be changing under the Affordable Care Act. Second, although the men invited to participate in this study were recruited from a list of all eligible men, selection bias may have occurred since some men may be more likely to participate in an interview than others in ways related to their specialist-seeking behaviors. Third, our findings are subject to recall bias. Participants were asked to describe experiences that occurred up to 28 months before the interview. How they actually made decisions at that time may be different from how they recalled them during interviews. Fourth, though our study population was recruited from a population-based cancer registry, few participants had coverage through Medicaid. The experiences of selecting a specialist may be different for this population if fewer physicians participate in Medicaid provider networks. 


\section{Conclusion}

Our findings revealed that despite the variations in specialist-seeking experiences among patients, most patients still relied primarily on referrals to diagnosing urologists by their PCPs and on referrals to treating specialists by their diagnosing urologists. Patients' trust in their referring providers causes referral patterns to have a larger than expected influence on treatment choice. Given how important the choice of specialist is for the eventual treatment that a patient receives, understanding this process is critical to better enable patients to receive preference-concordant care.

This study has important implications for PCPs, particularly since prostate cancer is the most common form of cancer among men and is thus frequently encountered in primary care practice. ${ }^{1}$ The fact that patients rely so heavily on PCPs to choose a specialist means that PCPs have an indirect but large influence on treatment choice. Currently, screening guidelines call for PCPs to engage in shared decision making to decide whether to screen a patient for prostate cancer. ${ }^{27}$ Our findings point to several possible roles for PCPs. First, revisiting patient preferences revealed during the decision to screen may be useful when discussing a referral to a specialist. Second, PCPs might stay involved throughout the initial evaluation for prostate cancer and suggest certain providers for second opinions who might offer a contrasting view of the initial specialist. This may be especially important for the group of passive patients who did not perform additional research into their care. PCPs may also directly participate in the discussion regarding the risks and benefits of different treatment options. $^{28-30}$ This may be particularly important for patients with lower educational attainment, who seem to rely even more on their PCP. Third, patients with a new cancer diagnosis often feel a sense of urgency to proceed with treatment, which limits how often they seek out more information. PCPs could, after an elevated prostate-specific antigen is found, counsel patients that it is safe to seek out more information, pursue second opinions, and weigh their options before making a decision.

The authors acknowledge and thank the Summer Undergraduate Minority Research Program (SUMR) at the Leonard Davis Institute of Health Economics at the University of Pennsylvania.
To see this article online, please go to: http://jabfm.org/content/ 30/2/220. full.

\section{References}

1. Centers for Disease Control and Prevention. Cancer among men. Last updated June 16, 2016. Available from: http://www.cdc.gov/cancer/dcpc/data/men. htm. Accessed October 10, 2015.

2. Cooperberg MR, Broering JM, Carroll PR. Time trends and local variation in primary treatment of localized prostate cancer. J Clin Oncol 2010;28: 1117-23.

3. Sommers BD, Beard CJ, D'Amico AV, Kaplan I, Richie JP, Zeckhauser RJ. Predictors of patient preferences and treatment choices for localized prostate cancer. Cancer 2008;113:2058-67.

4. Davidson BJ, Degner LF, Morgan TR. Information and decision-making preferences of men with prostate cancer. Oncol Nurs Forum 1995;22:1401-8.

5. Diefenbach MA, Dorsey J, Uzzo RG, et al. Decisionmaking strategies for patients with localized prostate cancer. Semin Urol Oncol 2002;20:55-62.

6. Gwede CK, Pow-Sang J, Seigne J, et al. Treatment decision-making strategies and influences in patients with localized prostate carcinoma. Cancer 2005;104: 1381-90.

7. Fischer M, Visser A, Voerman B, Garssen B, van Andel G, Bensing J. Treatment decision making in prostate cancer: patients' participation in complex decisions. Patient Educ Couns 2006;63:308-13.

8. Berry DL, Ellis WJ, Russell KJ, et al. Factors that predict treatment choice and satisfaction with the decision in men with localized prostate cancer. Clin Genitourin Cancer 2006;5:219-26.

9. Anandadas CN, Clarke NW, Davidson SE, et al. Early prostate cancer-which treatment do men prefer and why? Br J Urol 2010;107:1762-8.

10. Ihrig A, Keller M, Hartmann M, et al. Treatment decision-making in localized prostate cancer: why patients chose either radical prostatectomy or external beam radiation therapy. Br J Urol 2011;108: 1274-8.

11. Holmes-Rovner M, Stableford S, Fagerlin A, et al. Evidence-based patient choice: a prostate cancer decision aid in plain language. BMC Med Inform Decis Mak. 2005;5:16.

12. Lin GA, Aaronson DS, Knight SJ, Carroll PR, Dudley RA. Patient decision aids for prostate cancer treatment: a systematic review of the literature. CA Cancer J Clin 2009;59:379-90.

13. Adsul P, Wray R, Spradling K, Darwish O, Weaver $\mathrm{N}$, Siddiqui S. Systematic review of decision aids for newly diagnosed patients with prostate cancer making treatment decisions. J Urol 2005;194:1247-52.

14. Hoffman KE, Niu J, Shen Y, et al. Physician variation in management of low-risk prostate cancer: a 
population-based cohort study. JAMA Intern Med 2014;174:1450-9.

15. Fowler FJ, McNaughton CM, Albertsen PC, Zietman A, Elliott DB, Barry MJ. Comparison of recommendations by urologists and radiation oncologists for treatment of clinically localized prostate cancer. JAMA 2000;284:3217-22.

16. Pearce A, Newcomb C, Husain S. Recommendations by Canadian urologists and radiation oncologists for the treatment of clinically localized prostate cancer. Can Urol Assoc J 2008;2:197-203.

17. Kim S, Gross C, Nguyen P, et al. Specialty bias in treatment recommendations and quality of life among radiation oncologists and urologists for localized prostate cancer. Prostate Cancer Prostatic Dis 2014;17:163-9.

18. Cohen H, Britten N. Who Decides about Prostate Cancer Treatment? A qualitative study. Fam Pract 2003;20:724-9.

19. Freedman RA, Kouri EM, West DW, Keating NL. Racial/ethnic differences in patients' selection of surgeons and hospitals for breast cancer surgery. JAMA Oncol 2015;1:222-30.

20. Wilson CT, Woloshin S, Schwartz LM. Choosing where to go for major surgery: who makes the decision? Arch Surg 2007;142:242-6.

21. Schwartz LM, Woloshin S, Birkmeyer JD. How do elderly patients decide where to go for major surgery? Telephone interview survey. BMJ 2005;331: 821.

22. Abraham J, Sick B, Anderson J, Berg A, Dehmer C, Tufano A. Selecting a provider: what factors influ- ence patients' decision making? J Healthc Manag 2011;56:99-114.

23. Goodell S, Harris K, Buntin M. Choosing a health care provider: the role of quality information. Research synthesis report no. 14. Washington, DC: Robert Wood Johnson Foundation; 2008.

24. Harris KM. How do patients choose physicians? Evidence from a national survey of enrollees in employment-related health plans. Health Serv Res 2003;38:711-32.

25. Tu TH, Lauer JR. Word of mouth and physician referrals still drive health care provider choice. Washington, DC: Center for Studying Health System Change; 2008.

26. Victoor A, Delnoij DM, Friele RD, Rademakers JJ. Determinants of patient choice of healthcare providers: a scoping review. BMC Health Serv Res 2012; 12:272.

27. Loeb S. Guideline of guidelines: prostate cancer screening. BJU Int 2014;114:323-5.

28. Xu J, Janisse J, Ruterbusch J, Liu J, Holmes-Rovner M, Schwartz KL. Patients' survival expectations with and without their chosen treatment for prostate cancer. Ann Fam Med 2016;14:208-14.

29. Holmboe ES, Concato J. Treatment decisions for localized prostate cancer: asking men what's important. J Gen Intern Med 2000;15:694-701.

30. Agency for Healthcare Research and Quality. Knowing your options: a decision aid for men with clinically localized prostate cancer. Available from: https://www.effectivehealthcare.ahrq.gov/ehc/ decisionaids/prostate-cancer/. Accessed September 28, 2016. 